\title{
Towards Semi-Virtual Design Thinking - Creativity in Dispersed Multicultural and Multidisciplinary Innovation Project Teams
}

\author{
Beke Redlich $^{1}$, David Dorawa ${ }^{1}$, Dominik Siemon ${ }^{2}$, Christoph Lattemann ${ }^{1}$ \\ ${ }^{1}$ Jacobs University gGmbH ${ }^{2}$ University of Braunschweig \\ b.redlich|d.dorawa|c.lattemann@jacobs-university.de, d.siemon@tu-braunschweig.de
}

\begin{abstract}
This paper aims at examining whether the innovation approach Design Thinking (DT), which is usually performed in an analogue setting, can also be performed in a semi-virtual setting. We conducted an experiment comparing a fully analogue to a semivirtual DT workshop with overall 59 participants from 27 different countries and 11 different disciplines separated into an experimental- and control group. For the evaluation, we composed items from the psychological construct of Shared Mental Models (SMM) and discussed existing Media Theories in order to draw conclusions on the impact of performing DT semi-virtually in regard to using a digital whiteboard. Against our expectations and assumptions from theory, we reveal that a semi-virtual DT workshop can lead to high levels of shared understanding, satisfaction and perceived effectiveness. We argue that the applied digital whiteboard supports a creative semi-virtual collaboration due to its advanced functionalities, which supports the Media Richness Theory.
\end{abstract}

\section{Introduction}

Since the ongoing advancement of Information and Communication Technology (ICT), communication and collaboration holds new opportunities for teams to communicate and collaborate time- and/or location independent for different business purposes. A need for face-to-face collaboration becomes less necessary as audio and video-chat, shared documents, and other collaborative applications support the constantly rising number of virtual teams [1]. Furthermore, the increasing competition pressures companies to continuously innovate to find creative solutions [2]. Therefore, team creativity in virtual collaboration becomes an important issue for practice to perform and for science to investigate [3].

Past research focused either on cultural aspects or on psychological issues and competencies of team members, which was followed by examinations on teams and tasks [1]. More recent research emphasizes the need to analyze explicit innovation projects in virtual teams instead of testing certain tools [4].

This paper aims at examining whether the innovation approach Design Thinking (DT), which is usually performed in an analogue setting, can also be performed in a semi-virtual setting. DT is an approach that is inherently based on teamwork, creativity, collaboration and multidisciplinarity with the objective of developing innovative products, services or processes. The overall approach consists of three dimensions concerning the DT process, DT methods, and the DT mindset that shapes the interaction [5], [6].

Our paper incorporates research from various scientific fields on understanding virtual team performance. We particularly focus on the performance of creative and innovative virtual team. Therefore, we conducted an experiment that compared a completely analogue DT workshop with a semi-virtual DT workshop. 59 students from 27 different countries and 11 different undergraduate programs participated in this study. For the evaluation, we referred to items from the psychological construct of Shared Mental Models (SMM), in order to examine the level of shared understanding of team task and goal, satisfaction, and perceived effectiveness [7]-[10]. Our research presented in this paper deals with the underlying question whether if and how a semi-virtual DT workshop impacts team interaction in terms of the above-mentioned items.

Additionally, we evaluated the participants' application of a provided ICT-based tool and its functionalities - a digital whiteboard with task-specific functionalities - to get a deeper understanding of what an appropriate ICT tool in our context needs to offer.

In the following section, we will briefly present and discuss the major theoretical implications on creativity and virtual teams, DT and innovation as well as SMM. Additionally, we present a discussion on existing "Media Theories" as the underlying foundation for further discussions on technology fit. In section 3, we derive propositions from theory, we introduce the 
design of the experiment, the participants and procedures, measures as well as our results. Section 4 discusses our findings vis-á-vis the Media Theories. In the closing section, we conclude and provide suggestions for future research.

\section{Semi-Virtual Design Thinking}

Our overall intention to facilitating DT semivirtually is motivated by several major aspects. Therefore, we firstly discuss the underlying principles of DT. Further, we present past research on the link between creativity and (semi-)virtual teamwork. Afterwards, we introduce the psychological construct of SMM and relate this to DT and virtual teams. In the closing part of this section, we introduce a debate on Media Theories.

\subsection{Creativity, Innovation and Design Thinking}

Since on the one hand, dispersed workplaces and advanced ICT increase the existence of virtual collaboration, and on the other hand, a rising pressure for creative and innovative solution development is putting pressure on companies, there is a need to transform suitable approaches that successfully enable both aspects. DT is one approach for innovative collaboration that made his way successfully in the business world [11], [12]. DT can be labeled as a systematic approach that fuses multidisciplinary problem solving strategies in a sequence of phases that are shaped with various methods [6], [13], [14].

In summary, DT consists of a DT process, DT methods, and a DT mindset. The DT process is an iterative model that is based on phases: a phase for understanding and observing to build empathy, a phase for defining a point of view that radically changes the perspective to user's needs, an ideation-, prototyping-, and a testing phase. The order of the phases guarantees to apply different problem solving techniques originating from social science, design science, and engineering. This leads to the inclusion of deductive, inductive, and abductive reasoning, which encourages the development of (radical) innovations [13].

DT methods are - to a large extend - existing methodological approaches, borrowed from different disciplines, which are individually compiled due to the initial (design) challenge and team competencies. Examples are stakeholder analysis, journey maps, persona, prototyping, etc. [11], [15]-[17].

The DT process and methods are embedded in a DT mindset. The DT mindset frames the team interaction such as staying open-minded, leaving hierarchical orders, thinking outside the box and being creative as well as fostering multicultural- and multidisciplinary team arrangements [6], [18]. A skilled DT coach guarantees that the DT mindset as well as the DT process and DT methods are applied during teamwork.

DT is originally performed in analogue settings and its approach concerning phases, methods and mindset has proven to be successful for contemporary challenges companies have to face. We follow Rive and Karmoker (2016), who argue that an ICTsupported DT approach can also tackle contemporary business problems concerning dispersed collaboration and innovation pressure [19].

As business routines and challenges oftentimes result in a combination of face-to-face and virtual meetings during projects due to restrictions of resources (i.e. time and money), we decided to analyze the performance of a semi-virtual DT approach.

In principle, there are two approaches to design the environment for a semi-virtual DT. The technologybased approach is to examine existing or develop new ICT tools and test if they fit for DT [20]. The humancentered approach firstly analyzes the sociopsychological aspects of collaborative and creative teamwork and secondly to determine the underlying technology. We agree with Gilson et al. (2015) in arguing that diversity and creativity in virtual team interaction need more examination [1]. Hence, in our research, we follow the socio-psychological approach.

\subsection{Creativity in (Semi-) Virtual Teams}

When it comes to performing semi-virtual DT, past research concerning creativity aspects in virtual teamwork can be used as guidelines for our examination.

Virtual teams are constantly defined as being impacted by two major dimensions, which are geographical dispersion and technologically mediated communication [1], [21]. In general, this leads to less boundaries and an increase in location-independent collaboration, which is mediated via ICT [1], [22]. We focus on semi-virtual teamwork as a combination of face-to-face meetings as well as virtual collaboration. Past research shows that different types of virtual teams, such as semi-virtual teams, need further examination due to their specific needs and functioning [1], [21]. This is why this paper examines in particular semi-virtual DT. A pivotal element of DT is the creativity of the teams and their dynamic in the DT process.

Comparable to our research and experiment, past examinations argue that virtual teams are often used when it comes to specific projects [1]. Nonetheless, an appropriate examination with semi-virtual teams in 
specific projects, such as creative innovation projects are still missing.

Nevertheless, the aspect of creativity in virtual teams is already examined to a certain extent. Creativity can be defined as " $(\ldots)$ the production of novel, potentially useful ideas about work products, practices, services, or procedures” [3, p. 539], [23], [24]. Creative teamwork is fostered by the integration of diverse opinions, viewpoints, and experiences, etc., which can be supported by geographically-dispersed and diverse team members that contribute to one task [3], [25]-[28]. Hence, the opportunity of virtual collaboration via ICT can positively contribute to creativity in teams [1], [29]. In contrast, van Knippenberg and Schippers (2007) found that virtual collaboration for a shorter time frame might negatively contribute to the creative performance of a team [3], [30]. Mediating factors are the cultural diversity in the team and the number of members, as both factors negatively influence the complexity of collaboration [3], [31].

Based on these past findings, we argue that semivirtual teamwork in a short-time innovation project based on DT has a high level of creativity.

\subsection{Measuring Semi-Virtual DT with SMM}

In order to evaluate our semi-virtual DT approach, we use the psychological construct of SMM. SMM are the accumulation of several Mental Models in a team [32]-[34]. Mental Models are the internal representation of external impressions that an individual is exposed to and which determine the way someone acts and reacts in situations [32]. When it comes to teamwork, each team member has an own Mental Model and over the period of interaction an alignment of several Mental Models leads to SMM [35].

SMM are an indicator for successful teamwork and the evaluation of the measureable construct can state the level of shared understanding [36], [37]. Past research shows that especially in diverse team constellations the level of shared understanding is an important indicator for success [38]. Furthermore, past research has shown that a high level of SMM positively contributes to team creativity in short-term collaborations, which hence leads to successful teamwork [10], [39].

De Vreede et al. (2012) defined four categories of SMM knowledge structures [7]. Past research often focused on one of four structures, which we follow [7]: We, therefore, chose the knowledge structure "team task, goal, and performance requirements" [7]. Particularly this SMM reflects the object of our research, because it elucidates team interaction in a specific short-term project and it refers to the successful accomplishment of a solution for a given problem. Exactly this is what DT is about. We measure "performance requirements" by asking team members about their "satisfaction" and their "perceived effectiveness" of the group work.

\subsection{Media Theories for ICT Evaluation}

In this section, we will discuss Media Theories, which pinpoint effects on performance of workgroups applying ICT for collaboration.

There are three Media Theories that are considered important for our research: The Media Naturalness Theory (MNT), the Media Synchronicity Theory (MST), and the Media Richness Theory (MRT) [9], [40]-[42].

MNT expands on the idea of human evolution and argues that the usage of ICT suppresses major elements of face-to-face communication, which leads to perceptive barriers [40]. This argumentation does not take into account that current ICT open the opportunity for multichannel communication with diverse opportunities such as synchronous, audio-, and visual communication [43].

In contrast to MNT, MST argues that communication can even be improved when a given ICT allows for the appropriate speed of synchronicity that a process of communication requires [9], [41]. Furthermore, MRT posits that the level of appropriate functionality, which an ICT inherits, influences the effectiveness of the usage. The richer a medium for communication, the more effective it is [42].

The examination of our semi-virtual DT approach in regard to Media Theories shall give a ground for discussion on the fit of our chosen technology and, therefore, create an understanding which functionalities of our chosen ICT - a digital whiteboard - were used during application [1], [3]. Furthermore, past research shows that multiculturalism in virtual teams has distinct negative effects on the process, and moreover affects the level of creativity [3]. In contrast, other studies show consistent levels of creativity in virtual, multicultural teamwork irrespective to the choice of ICT [1]. Nonetheless, an advanced examination for specific ICT that supports the usage in particular creative settings are missing [1].

\section{Propositions}

The presented theoretical discussion shows the relevance and necessity of a deeper examination of semi-virtual teamwork in general, and on creative teamwork (DT) in particular. 
We aim at examining whether semi-virtually performed DT is as successful as analogue performed DT. Successfulness in this context relates to the level of SMM, which shall indicate whether team members evaluate their team performance positively in respect to the applied knowledge structure. In this paper, we test whether the usage of a given virtual tool - a digital whiteboard with specific functionalities - works as appropriate alternative compared to collaboration on an analogue whiteboard with multiple functionalities, which foster creativity in a DT workshop. Our major research questions (RQ) are:

(1) How is the level of SMM in a DT workshop impacted when teamwork is performed in a semi-virtual setting?

(2) Is a digital whiteboard an appropriate tool to support semi-virtual DT workshops?

(3) Which functionalities of a digital whiteboard are needed to appropriately support the development of SMM in a semi-virtual DT Workshop?

To answer the above-mentioned research questions one and two, we evaluate the influences of the level of shared understanding, satisfaction, and perceived effectiveness based on the psychological construct of SMM, specifically the knowledge structure "team task, team goal and performance requirements" in a semivirtual DT setting compared to an analogue DT setting. We propose that a semi-virtually performed DT workshop with the support of a digital whiteboard...

1. ...leads to a low shared understanding of teams compared to an analogue setting.

2. ...leads to a low level of satisfaction for team members in comparison to an analogue setting.

3. ...is perceived with low effectiveness compared to an analogue setting.

These propositions are based on findings concerning MNT, which argues that the usage of ICT hinders certain cognitive processes and, therefore, is not as effective as an analogue collaboration [40]. Since SMM are an indicator for shared cognitive representations to perform team interaction, we propose that the level of shared understanding, satisfaction, and perceived effectiveness is low in comparison to an analogue performance [7], [44]. The term "low" indicates a rating of less than neutral in a 5point Likert-scale.

Complementary, to draw further conclusions for our research question two and give answer to three, we evaluate whether the usage of a digital whiteboard with its diverse functionalities supports a semi-virtual DT workshop appropriately. This is reached via an additional survey for the experimental group on the preferred use of functionalities within the given tool. Additionally, this will be related to the above presented Media Theories to draw further conclusions.

Fig. 1 Evaluation Design

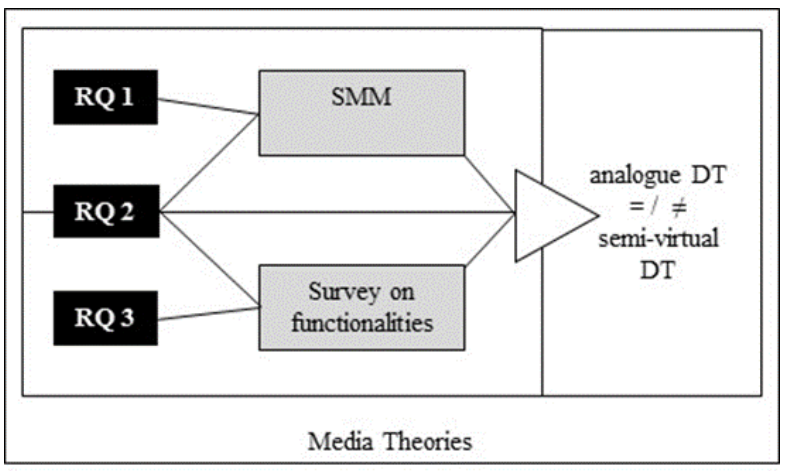

\section{Design}

For the purpose of the experiment, we developed one DT workshop concept that follows the requirements of defining a phase sequence and methods from different disciplines and were, hence, applied for the experimental- and control group. Each workshop was stretched over three days and included the phases understand, observe, point of view, ideate, prototype, and test. In-between the predefined timeslots for performing the phases there was time left for potential iteration of the team process. For each phase at least two methods were used to shape the process. The following methods were used in the specific phases:

Understand: The teams were asked to brainstorm and use the method "Define your Audience", a visual method that asks the team members to identify all stakeholders that are relevant for the design challenge [15]. Additionally, the needs of the stakeholders are outlined.

Observe: The method "Interview for Empathy" was conducted in order to build up empathy with stakeholders while asking specifically designed questions [45]. Based on the findings from the interviews, a "Journey Map" for a sample of stakeholders was created by the team members to generate insights [16].

Point of View: In this phase a bundle of "Persona" were developed, which are fictional characters based on the insights from observation [17]. Afterwards, the method "Create Insight Statement" was used for each Persona, which in turn leads to the adjustment of the 
initial design challenge from a user-centered perspective [46].

Ideate: For the ideation phase "Brainstorming" was used to generate ideas. Based on this, the method "Gut Check" was applied to arrange and expand idea bundles [47].

Prototype: The team members were free to choose from either material prototypes, roleplay, storyboard or IT prototypes such as mock-ups.

Test: The developed prototypes were tested in a World Café, where stakeholders and experts were able to give feedback on the solution. Afterwards, the prototypes were improved by the team members based on the feedback from others.

The DT workshop took place in a dedicated DT lab, which is flooded with natural light, where all furniture and equipment is moveable, and colorful consumables are provided.

The semi-virtual setting refers to the realization of specific phases in a location-independent manner. The phases "Understand" and "Ideate" were executed location-independent with all team members of one team. This procedure is supported by Baskerville and Nandhakumar (2007) who argue that communication and collaboration are attached to team members and not to places [1], [48]. The instructions of how to use particular methods were given in advance in a face-toface setting before team members spread out. All team members used a given digital whiteboard and were free to use additional ICT for communication, such as skype, WhatsApp, FaceTime or iMessage. The decision which ICT to use, was left to each team since it opens the opportunity that teams apply their existing ICT and do not need to get used to two new applications. This procedure is supported by past research, which argues that participants shall feel comfortable with technology usage in order to support interaction [3].

\subsection{A Digital Whiteboard for Semi-Virtual DT}

For the purpose of performing a semi-virtual DT workshop an appropriate software needs to be applied. In a common analogue DT setting, whiteboards are the preferred medium for collaboration. Whiteboards allow for a collaborative visualization of content to collectively create insights [49]. Furthermore, the opportunity for changing and erasing visual content supports the building of common visual representations, which fosters the level of SMM [39], [50]. We, therefore, apply a digital whiteboard for the objective of performing a semi-virtual DT workshop.

There are several digital whiteboards available. We chose to use "Mural.co" [51]. Mural.co is a web-based software that allows for real-time collaboration, communication, and visualization with multiple users. Mural.co has an intuitive usability and integrates various functionalities that an analogue whiteboard offers as well. Collaborative visualization in this software includes the functionalities of using post- it notes, forms-, shapes-, connections-, text-, and photo insertion as well as using predefined templates such as a Business Model Canvas. Communication is additionally supported with a real-time chat. Furthermore, Mural.co offers the functionality for collaborative voting on content and tracking of single activities in a protocol to allow for traceability of single actions [51].

The combination of functionalities as well as an easy subscription process, convinced us to use Mural.co as support for the semi-virtual DT workshop.

\subsection{Participants and Procedures}

Our experiment involved overall 59 students from diverse undergraduate programs such as Economics, Management, Industrial Engineering, Computer Science, Social Sciences, Intelligent Mobile Systems, Electrical \& Computer Engineering, Politics \& History, Physics, Biochemistry \& Cell Biology, and Medicinal Chemistry \& Chemical Biology. The age of the participants ranged from 19 to 22 years and the group consisted of 36 male and 23 female participants. The participants were born in 27 different countries throughout the world. The experiment was executed within an extracurricular professionalization offer but the participation in the experiment was mandatory. The experiment lasted 6 days - three days for the control group (CG) and three days for the experimental group (EG). The allocation to either the CG or the EG was coordinated via an official and automated extracurricular activity registration tool with no possibility for manipulating the groups. The group sizes varied due to automated registration and institutional conditions, which led to a group size of NcG $=24$ for the control group (analogue workshop) and $\mathrm{NEG}=35$ for the experimental group (semi-virtual workshop). The distribution of the participants resulted in six teams for either CG or EG. The team size varied between four to six team members each.

Prior to the beginning of the experiment, all participants took part in a one-day session on the introduction to DT, where the theory and ideas of DT were explained and a one-hour design challenge was performed. Furthermore, the teams prepared their own design challenges as the starting point for the three-day workshops, which were accompanied by dedicated DT coaches. 


\subsection{Measures}

In order to test our propositions, we conducted a survey based on previously defined concepts [8], [10], [52]. After each DT workshop the participants of the EG and CG filled out the digital form individually and were invited to rate their perception on the dependent measures shared understanding, satisfaction, and perceived effectiveness on a 5-point Likert-scale. We defined the measures in the following way:

The measure "shared understanding of team task, goals" is based on findings from Johnson et al. (2007) and Santos et al. (2015) and is sampled as a plausible construct for the measurement of team-related acquaintance [8], [10]. This measure includes 15 items on shared understanding of team task and goal related perception, communication, and team climate.

The measure "satisfaction" contains six items based on findings from Dennis et al. (1996) and Santos et al. (2015) [10], [52]. This measure evaluates the individual level of every participant's perception according to satisfaction with the performance of a semi-virtual DT approach.

The measure "perceived effectiveness" includes three items based on findings from Dennis et al. (1996) [52]. These items evaluate the perceived effectiveness concerning the focus on problem-solving, input of individual skills, and task structuring.

The survey contains 24 questions. All items used in the measures are weighted equally and included in the statistical calculations. We calculated the internal consistency with Cronbach's Alpha $(\alpha)$ for each measure, to validate that all items measure the same concept (Table 1) [53], [54]. Due to the use of Likertscales, we measured Mann-Whitney $U$ (U) tests to validate whether there is a significant difference in the results of the EG and the CG. Based on this, we computed the Spearman correlation for every measure. Furthermore, we asked the participants of the EG which functionalities they used while using the digital whiteboard. Multiple answers were possible in a selection of the following functionalities: post-it notes, text insertion, photo insertion, voting system, predefined templates, chat function, shapes and connections, and icons. Furthermore, the participants had the choice of typing in feedback what they liked and what they disliked about using Mural.co [51].

\subsection{Results}

Based on the answers from the survey, we calculated $\alpha$, which validates that all items measure the same concept. Table 1 shows the results of the survey in comparison of the CG and EG, inclusive standard deviations (SD), and $\alpha$.

Tab. 1. Descriptive data

\begin{tabular}{lccccc}
\hline \multicolumn{1}{c}{ Measure } & Mean $^{C G}$ & Mean $^{E G}$ & $S D^{C G}$ & $S D^{E G}$ & $\alpha$ \\
\hline Shared & & & & & \\
$\begin{array}{l}\text { understanding } \\
\text { Satisfaction }\end{array}$ & 4.583 & 4.337 & .617 & .680 & .923 \\
$\begin{array}{l}\text { Perceived } \\
\text { effectiveness }\end{array}$ & 4.417 & 4.400 & .629 & .658 & .848 \\
\hline
\end{tabular}

The results show that the EG evaluated the team interaction concerning shared understanding, satisfaction, and perceived effectiveness slightly lower in comparison to the CG. The results show an insignificant difference of both groups.

Because of the existence of non-normal distributed data and the usage of Likert-scales within the survey, we additionally calculated $U$ (Table 2). Due to the comparably small number of participants in the experiment and the insignificant results, we additionally computed effect size with Cohen's d (d).

Tab. 2. Mann-Whitney $U$ tests

\begin{tabular}{|c|c|c|c|c|}
\hline Measure & $U$ & $d$ & $Z$ & $p$ \\
\hline $\begin{array}{l}\text { Shared } \\
\text { understanding }\end{array}$ & 275.5 & 0.379 & 2.491 & .025 \\
\hline Satisfaction & 328.5 & 0.219 & 1.428 & .153 \\
\hline $\begin{array}{l}\text { Perceived } \\
\text { effectiveness }\end{array}$ & 350.5 & 0.188 & 1.095 & .273 \\
\hline
\end{tabular}

The results of the $\mathrm{U}$ tests validate that there is no significant difference between the EG and the CG. To further draw conclusions on the insignificant results, we computed a Spearman correlation ( $\rho$ ) (Table 3).

Tab. 3. Spearman Correlation

\begin{tabular}{lcc}
\hline \multicolumn{1}{c}{ Measure } & $\rho$ & $\mathrm{p}$ \\
\hline $\begin{array}{l}\text { Shared understanding and } \\
\text { satisfaction }\end{array}$ & 0.773 & $7.561 \mathrm{e}-13$ \\
$\begin{array}{l}\text { Shared understanding and } \\
\text { perceived effectiveness }\end{array}$ & 0.747 & $1.038 \mathrm{e}-11$ \\
$\begin{array}{l}\text { Perceived effectiveness and } \\
\text { satisfaction }\end{array}$ & 0.691 & $1.434 \mathrm{e}-09$
\end{tabular}

The Spearman correlation coefficient $\rho$ measures the monotonic relationship of two variables and the results show that the correlation of the measures perceived effectiveness and satisfaction represent a moderate uphill positive relationship $(\rho=.691)$. The correlation of the measure satisfaction and shared understanding $(\rho=.773)$ as well as shared 
understanding and perceived effectiveness $(\rho=.747)$ represent a strong uphill positive linear relationship.

Additionally, we asked the participants of the EG questions on the usage of Mural.co. Every participant strongly agreed that Mural.co is an appropriate whiteboard for location-independent teamwork.

Fig. 2 Use of single functionalities

\begin{tabular}{l|r}
\hline Chat & $91,4 \%$ \\
\cline { 2 - 2 } Post-it notes & $88,6 \%$ \\
Text & $82,9 \%$ \\
Shapes/Connections & $77,1 \%$ \\
Icons & $25,7 \%$ \\
Voting & $11,4 \%$ \\
Templates & $11,4 \%$ \\
Photo & $5,7 \%$ \\
\hline
\end{tabular}

Concerning the use of specific functionalities when using Mural.co, the participants of the EG stated that the chat, post-it notes, text insertion, and shapes and connections were frequently used (Figure 2). In contrast, the functionalities of inserting icons, using the voting system, predefined templates, and photo insertion were less frequently or rarely used.

\section{Discussion}

Our research aims at developing a semi-virtual DT approach that supports companies in facilitating semivirtual teamwork regarding creative innovation projects. In our experiment, we tested a semi-virtual DT approach in comparison to an analogue one. For the evaluation of our research, we introduced SMM as a measurable construct to make a statement on shared understanding, satisfaction, and perceived effectiveness. Additionally, we asked the participants of the EG to state, which functionalities of the digital whiteboard were used most frequently in order to answer which functionalities of the tool support semivirtual DT. Furthermore, we introduced three existing Media Theories - MRT, MNT, and MST - to be able to evaluate the fit and functionality of the digital whiteboard that was used during the experiment.

Based on the theoretical basis at the beginning of our paper, we discuss the results of the survey in regard to our propositions.

In proposition 1 , we predicted that a semi-virtual DT workshop leads to a low shared understanding of teams in contrast to an analogue setting. We can outline that this proposition 1 is false, since the results show an insignificant difference and the level of shared understanding is minimally lower in the EG than in the CG. The results evoke that the level of shared understanding in the semi-virtual DT setting was comparably high, which indicates a positive, successful collaboration. The results of the experiment are opposing with findings from van Knippenberg and Schippers (2007) who state that virtual collaboration for a short-time frame might negatively contribute to the teams creative performance [30]. Our experiment structure and setting of a time-restricted semi-virtual DT workshop that is based on creative interaction shows a high level of shared understanding. The results are, therefore, in line with Mathieu et al. (2008) who state that virtual collaboration can positively contribute to creative teamwork [29].

In line with proposition 1 , we argued in proposition 2 that a low level of satisfaction can be found in semivirtual DT workshops in comparison to an analogue one. The results disprove our proposition 2, since the rated level of satisfaction is high. This is also contrary in regard to findings from Martins and Shalley (2011) who state that multiculturalism affects the process of virtual collaboration negatively [3]. Our experiment included collaboration of people from 27 countries who rated a high level of satisfaction concerning their teamwork. The participants of the EG rated their perceived satisfaction $1.5 \%$ less in comparison with the CG, which indicates that neither the multicultural team constellations nor the semi-virtual collaboration negatively impacted the DT workshops.

In proposition 3, we predicted that a semi-virtual DT workshop is perceived with low effectiveness compared to an analogue setting. Again, the proposition 3 is disproved by the results of the experiment. The level of perceived effectiveness of the experiment's participants is high in the CG as well as in the EG. The results of the experiment are in line with the assumptions of Gilson et al. (2015) who propose that negative effects due to virtual collaboration are less dominant in teams that represent younger generations [1]. According to the participants' ages ranging from 19 to 22 years, a negative effect regarding a perceived level of effectiveness can be explained due to the generation's familiarity with ICT.

The reflection on our propositions in comparison with the results from the experiment, show that a semivirtually performed DT workshop does not have negative effects on the shared understanding, satisfaction, and perceived effectiveness of the participants. The survey shows that all items of the SMM knowledge structure "team task, goal and performance requirements" reached a high level, which is an indicator for successful collaboration. This finding is supported by Bittner and Leimeister (2014) who state that for SMM, especially in a diverse team constellation, a high level of shared understanding is an essential indicator for success [38]. Accordingly, our 
research question "How is the level of SMM in a DT workshop impacted when teamwork is performed in a semi-virtual setting?" can be answered with a positive résumé.

Concerning our research question whether a digital whiteboard is an appropriate support for semi-virtual DT workshops, we can argue that our chosen digital whiteboard Mural.co creates an overall satisfactory support. This is in line with the questioning of the experiment's participants of the EG. The results also coincide with findings from $\mathrm{Ju}$ et al. (2006) who state that flexibility of collaborative visualization, which a whiteboard offers, supports the building of SMM [50].

Furthermore, all EG teams came to a satisfying output at the end of the semi-virtual DT workshop, which indicates that the usage of Mural.co supported the process towards a satisfactory output. This is in line with findings from Gilson et al (2015) who summarize that a constant level of creative and multicultural collaboration can be achieved regardless the choice of ICT [1].

Our survey of the EG, moreover, delivered information on the functionalities a digital whiteboard needs to inherit in order to support the development of SMM in a semi-virtual DT workshop. The results show that post-it notes, text insertion, and shapes and connections were the most preferred functions used in virtual team collaboration. Additionally, the chat function of Mural.co was rated most common. Although, the participants were free to use any additional audio-visual application in regard to personal claims, most participants used the integrated chat function of our suggested digital whiteboard. As stated earlier, findings from literature indicate that if participants use well-known ICT, a level of comfortableness positively influences team interaction [3]. The results of the experiment indicate that comfortableness towards ICT usage might also be achieved via integrated functionalities of one application such as a usually commonly-known chat function.

Other functionalities provided by Mural.co such as a voting system, photo insertion, predefined templates, and icons were in comparison less frequently used. We propose that these less used functionalities might become more important, when different tasks during virtual collaboration are performed. Photo insertion, for example, might play a more important role, when other methods such as the creation of storyboards are applied.

Eventually, the rating of the participants on the usage of specific functionalities reveal a response to our research question "Which functionalities of a digital whiteboard are needed to appropriately support the development of SMM in a semi-virtual DT Workshop?”.

In conclusion, we can reveal that our propositions, which are based on the MNT, cannot be supported. The results of the experiment show positive levels of SMM, which indicate that cognitive processes were not hindered during semi-virtual collaboration. Accordingly, we disprove the relation of MNT in the context of our experiment.

Furthermore, we cannot verify a connection to MST since the evaluation did not measure the speed of synchronicity of virtual communication.

Based on the discussion, we rather propose that the success of the semi-virtual DT workshops is in line with MRT, as the evaluation of the applied digital whiteboard revealed a rich usage of functionalities that are provided by the software and used by the experiment's participants.

\section{Conclusion}

This paper examined whether the innovation approach DT, which is usually performed in an analogue setting, can also be performed in a semivirtual setting.

We, therefore, conducted an experiment that followed the requirements of a DT approach. On the basis of the psychological construct of SMM, we evaluated our semi-virtual DT approach in comparison to an analogue DT workshop. The discussion on existing Media Theories served as an underlying foundation for the evaluation of our applied software, a digital whiteboard.

In summary, we can outline that our propositions have been proven wrong. The results show that there are no negative effects of the level of SMM when performing DT semi-virtually. This, consequently, disproves our assumption that an ICT-supported collaboration hinders cognitive processes, as predicted according to MNT.

This research rather reveals that a semi-virtual DT workshop can lead to high levels of shared understanding, satisfaction and perceived effectiveness. We argue that the applied digital whiteboard supports a creative semi-virtual collaboration due to the advanced functionalities. Based on this finding, we draw a connection to MRT.

Furthermore, we admit that our research has limitations concerning the number participants. Additionally, as we aim at developing a semi-virtual DT approach for the benefit of companies to improve innovation development, an experiment with employees would be of advantage. Even though, there is a need for further research to prove different 
conditions of semi-virtual DT, this research shows that a strictly designed semi-virtual DT workshop with the support of appropriate ICT leads to a successful collaboration, which is a first step for improving business challenges in this context.

\section{Acknowledgements}

This study is part of the project "DETHIS - Design Thinking for Industrial Services", funded by the Federal Ministry of Education and Research (BMBF) of Germany, Grant 02K14A140.

\section{References}

[1] L. L. Gilson, M. T. Maynard, N. C. J. Young, M. Vartiainen, and M. Hakonen, "Virtual Teams Research 10 Years, 10 Themes, and 10 Opportunities,” J. Manag., 2015, pp. 1313-1337.

[2] T. M. Amabile, “A Model of Creativity and Innovation in Organizations,” 1988.

[3] L. L. Martins and C. E. Shalley, "Creativity in Virtual Work: Effects of Demographic Differences,” Small Group Res., 2011, pp. 536-561.

[4] N. A. Ebrahim, "Virtual R\&D Teams: A New Model for Product Development,” Int. J. Innov., 2015, pp. 1-27.

[5] T. Lindberg, E. Köppen, I. Rauth, and C. Meinel, "On the Perception, Adoption and Implementation of Design Thinking in the IT Industry,” in Design Thinking Research, H. Plattner, C. Meinel, and L. Leifer, Eds. Springer Berlin Heidelberg, pp. 229-240, 2012.

[6] L. Carlgren, I. Rauth, and M. Elmquist, "Framing Design Thinking: The Concept in Idea and Enactment," Creat. Innov. Manag. 2016, pp. 38-57.

[7] T. De Vreede, I. Boughzala, G.-J. De Vreede, and R. Reiter-Palmon, "A model and exploratory field study on team creativity," in System Science (HICSS), 2012 45th Hawaii International Conference on, 2012, pp. 227-236.

[8] T. E. Johnson, Y. Lee, M. Lee, D. L. O’Connor, M. K. Khalil, and X. Huang, "Measuring Sharedness of TeamRelated Knowledge: Design and Validation of a Shared Mental Model Instrument,” Hum. Resour. Dev. Int., 2007, pp. 437-454.

[9] A. R. Dennis, R. M. Fuller, and J. S. Valacich, "Media, Tasks, and Communication Processes: A Theory of Media Synchronicity,” MIS Q, 2008, pp. 575-600.

[10] C. M. Santos, S. Uitdewilligen, and A. M. Passos, "Why is Your Team More Creative Than Mine? The Influence of Shared Mental Models on Intra-group Conflict, Team Creativity and Effectiveness," Creat. Innov. Manag., 2015, pp. 645-658.

[11] A. Efeoğlu, C. Møller, and M. Sérié, "Solution Prototyping with Design Thinking - Social Media for SAP Store: A Case Study,” in Design Science: Perspectives from Europe, 2013, pp. 99-110.

[12] D. Dunne and R. Martin, "Design Thinking and How It Will Change Management Education: An Interview and Discussion,” Acad. Manag. Learn. Educ., 2006, pp. 512-523.
[13] M. Lande, N. Sonalkar, M. Jung, C. Han, and S. Banerjee, "Monitoring Design Thinking Through In-Situ Interventions,” in Design Thinking Research, H. Plattner, C. Meinel, and L. Leifer, Eds. Springer Berlin Heidelberg, 2012, pp. 211-226.

[14] M. Stickdorn and J. Schneider, This is Service Design Thinking: Basics, Tools, Cases. Consortium Book Sales \& Dist, 2010.

[15] IDEO.ORG, “Define your Audience," Design Kit. [Online]. Available: http://www.designkit.org/methods/11. [Accessed: 14-Jun-2017].

[16] IDEO.ORG, “Journey Map,” Design Kit. [Online]. Available: http://www.designkit.org/methods/63. [Accessed: 14-Jun-2017].

[17] K. Goodwin, Designing for the Digital Age: How to Create Human-Centered Products and Services. John Wiley \& Sons, 2011.

[18] I. Rauth, E. Köppen, B. Jobst, and C. Meinel, “Design Thinking: An Educational Model towards Creative Confidence," 66-2 Proc. 1st Int. Conf. Des. Creat. ICDC 2010, 2010.

[19] P. Rive and S. Karmoker, "Design Thinking Methods and Creative Technologies in Virtual Worlds,” in Academic Conference International Limited, 2016, pp. 635-644.

[20] M. Wenzel, L. Gericke, C. Thiele, and C. Meinel, "Globalized Design Thinking: Bridging the Gap Between Analog and Digital for Browser-Based Remote Collaboration," in Design Thinking Research, Springer, Cham, 2016, pp. 15-33.

[21] J. Webster and W. K. P. Wong, "Comparing traditional and virtual group forms: identity, communication and trust in naturally occurring project teams," Int. J. Hum. Resour. Manag., 2008, pp. 41-62.

[22] K. K. Myers and K. Sadaghiani, "Millennials in the Workplace: A Communication Perspective on Millennials' Organizational Relationships and Performance," J. Bus. Psychol., 2010, pp. 225-238.

[23] T. M. Amabile, R. Conti, H. Coon, J. Lazenby, and M. Herron, "Assessing the Work Environment for Creativity," Acad. Manage. J., 1996, pp. 1154-1184.

[24] C. E. Shalley, "Effects of Coaction, Expected Evaluation, and Goal Setting on Creativity and Productivity," Acad. Manage. J., 1995, pp. 483-503.

[25] A. B. Hargadon and B. A. Bechky, "When Collections of Creatives Become Creative Collectives: A Field Study of Problem Solving at Work,” Organ. Sci., 2006, pp. 484-500.

[26] S. Taggar, "Individual Creativity and Group Ability to Utilize Individual Creative Resources: A Multilevel Model,” Acad. Manage. J., 2002, pp. 315-330.

[27] R. W. Woodman, J. E. Sawyer, and R. W. Griffin, "Toward a Theory of Organizational Creativity," Acad. Manage. Rev., 1993, pp. 293-321.

[28] F. J. Milliken, C. A. Bartel, and T. Kurtzberg, "Diversity and creativity in work groups: A dynamic perspective on the affective and cognitive processes that link diversity and performance," in Group Creativity: Innovation through Collaboration, P. B. Paulus and B. A. Nijstad, Eds. Oxford University Press, 2003.

[29] J. Mathieu, M. T. Maynard, T. Rapp, and L. Gilson, "Team Effectiveness 1997-2007: A Review of Recent 
Advancements and a Glimpse Into the Future,” J. Manag., 2008, pp. 410-476.

[30] D. van Knippenberg and M. C. Schippers, "Work Group Diversity,"

http://dx.doi.org/10.1146/annurev.psych.58.110405.085546,

06-Dec-2006. [Online]. Available:

http://www.annualreviews.org/doi/10.1146/annurev.psych.58

.110405.085546. [Accessed: 12-Jun-2017].

[31] D. Zhang, P. B. Lowry, L. Zhou, and X. Fu, "The Impact of Individualism--Collectivism, Social Presence, and Group Diversity on Group Decision Making Under Majority Influence,” J. Manag. Inf. Syst., 2007, pp. 53-80.

[32] W. B. Rouse and N. M. Morris, "On looking into the black box: Prospects and limits in the search for mental models,” Psychol. Bull., 1986, pp. 349-363.

[33] J. A. Cannon-Bowers and E. Salas, "Reflections on shared cognition,” J. Organ. Behav., 2001, pp. 195-202.

[34] J. A. Cannon-Bowers, E. Salas, and S. Converse, "Shared Mental Models in Expert Team Decision Making," in Individual and Group Decision Making: Current Issues, N. J. Castellan, Ed. Psychology Press, 2013.

[35] J. E. Mathieu, T. S. Heffner, G. F. Goodwin, E. Salas, and J. A. Cannon-Bowers, "The influence of shared mental models on team process and performance,” J. Appl. Psychol., 2000, pp. 273-283.

[36] R. Klimoski and S. Mohammed, “Team Mental Model: Construct or Metaphor?,” J. Manag., 1994, pp. 403-437.

[37] B.-C. Lim and K. J. Klein, "Team mental models and team performance: a field study of the effects of team mental model similarity and accuracy,” J. Organ. Behav., 2006, pp. 403-418.

[38] E. A. C. Bittner and J. M. Leimeister, "Creating Shared Understanding in Heterogeneous Work Groups: Why It Matters and How to Achieve It," J. Manag. Inf. Syst., 2014, pp. 111-144.

[39] B. Redlich, D. Siemon, C. Lattemann, and S. RobraBissantz, "Shared Mental Models in Creative Virtual Teamwork," Proceedings of the 50th Hawaii International Conference on System Sciences. 2017, pp. 464-473.

[40] N. Kock, “The Psychobiological Model: Towards a New Theory of Computer-Mediated Communication Based on Darwinian Evolution,” Organ. Sci., 2004, pp. 327-348.
[41] A. R. Dennis and J. S. Valacich, "Rethinking media richness: towards a theory of media synchronicity," Proceedings of the 32nd Annual Hawaii International Conference on Systems Sciences, 1999, pp. 1-10.

[42] R. L. Daft and R. H. Lengel, "Organizational Information Requirements, Media Richness and Structural Design,” Manag. Sci., 1986, pp. 554-571.

[43] A. P. Schouten, B. van den Hooff, and F. Feldberg, "Virtual Team Work Group Decision Making in 3D Virtual Environments," Commun. Res., 2016, pp. 180-210.

[44] M. T. Maynard and L. L. Gilson, "The Role of Shared Mental Model Development in Understanding Virtual Team Effectiveness,” Group Organ. Manag., 2014, pp. 3-32.

[45] d.school Stanford, Ed., "Interview for Empathy." d.school Stanford. [Online] Available: https://dschoolold.stanford.edu/wp-content/themes/dschool/methodcards/interview-for-empathy.pdf, d.school Stanford.

[46] IDEO.ORG, “Create Insight Statements," Design Kit. [Online]. Available: http://www.designkit.org/methods/62. [Accessed: 14-Jun-2017].

[47] IDEO.ORG, “Gut Check,” Design Kit. [Online]. Available: http://www.designkit.org/methods/42. [Accessed: 14-Jun-2017].

[48] R. Baskerville and J. Nandhakumar, “Activating and Perpetuating Virtual Teams: Now That We're Mobile, Where Do We Go?,” IEEE Trans. Prof. Commun., 2007, pp. 17-34.

[49] J. Walny, S. Carpendale, N. H. Riche, G. Venolia, and P. Fawcett, "Visual Thinking In Action:Visualizations As Used On Whiteboards,”, 2011, pp. 1-10.

[50] W. Ju, L. Neeley, T. Winograd, and L. Leifer, “Thinking with erasable ink: Ad-hoc whiteboard use in collaborative design,” CDR Tech. Rep., 2006, p. 52.

[51] M. Suarez-Battan, "Mural,” Mural. [Online]. Available: https://mural.co/. [Accessed: 23-Aug-2016].

[52] R. Dennis, J. S. Valacich, T. Connolly, and B. E. Wynne, "Process Structuring in Electronic Brainstorming," Inf. Syst. Res., 1996, pp. 268-277.

[53] L. J. Cronbach, "Coefficient alpha and the internal structure of tests," Psychometrika, 1951, pp. 297-334.

[54] M. Tavakol and R. Dennick, "Making sense of Cronbach’s alpha,” Int. J. Med. Educ., 2011, pp. 53-55, Jun.. 